\title{
Research on the use of modelling and computer simulation for metal mining structures in order to increase quality and safety
}

\author{
Cosmin Vitan ${ }^{1 *}$, Marin Sivliu Nan ${ }^{1}$, Iosif Dumitrescu ${ }^{1}$, Aurelian Nicola ${ }^{1}$ and Dorel Vitan ${ }^{1}$ \\ ${ }^{1}$ University of Petrosani, 20 University street, 332006, Petrosani, Romania.
}

\begin{abstract}
D representations using assisted design and computer simulations allow determining the geometric characteristics of critical sections needed for analytical calculation. Also, these representations form the basis of meshing necessary for the finite element calculation.

The purpose of this paper is to perform the metal structure verification, both by classical analytical calculation and by the finite element method, as well as to validate these calculations by computerized simulation.

The calculation performed on this metallic structure involves the analytical determination of stresses and, implicitly, of safety coefficients, which constitute a verification of metal structure.
\end{abstract}

\section{Introduction}

This paper approaches the location, manufacturing and operational safety of the equipment for digging the de-aeration well, which represents an underground hydro- technical work meant for evacuating the air from the water conveyed through the underground mine shafts. For this purpose, in accordance with a series of theoretical and experimental researches, the technical solution for carrying out this objective has been elaborated. The solution considers the special conditions determined by altitude, location, available space, lack of electrical energy, difficult access, etc.

For these reasons and with a view to provide the general manufacturing quality and operational safety of the metal tower of the digging equipment, a series of theoretical calculation elements have been used together with the modelling and simulation of the stress occurring within the metal structure of the tower and the use of various software for similar situations. Comparing the results given by the previously mentioned approach represents the main topic of this scientific research.

The pit-head frame, 3D-displayed in the utility software Solid Edge in Figures 1 and 2, represents a mixed metal structure, mostly removable, made of L160 and L100 angle profiles, gussets and connecting elements put together through welding, but mainly through screws. It is a metal structure including three sections, with a square section whose side measures $5 \mathrm{~m}$ and a functional height that reaches the mounting bridge of the $16 \mathrm{~m}$ hoisting sheave.

The calculation performed on this metal structure involves the analytical determination

Cosmin Vitan: vitan.daniel.cosmin@gmail.com 
of stresses and, implicitly, of safety coefficients, which represents a calculation verification of the metal structure; the analytical calculation also analyses the connection between the metal pit-head frame and the anchorage cables together with the stress systems; the determination of the stresses and distortions in the method of the finite element, while using two calculation software, Cosmos and Abaqus; comparing the results through putting into practice the specified methods and interpreting the results.

The 3D-representations that employ assisted designing used by Solid Edge allow the determination of the geometrical characteristics of the critical sections required in order to perform the analytical calculation. Meanwhile, this representation constitutes the basis for the digitization of finite element calculation. [1]

Figure 1a) it is presented 3D-model of the pit-head frame, with the following elements: 1 - lower section; 2 - intermediate section; 3 - upper superior; 4 - junction plates between sections; 5 - upper platform 1;6-upper platform 2 . Figure $1 \mathrm{~b}$ ) it shown the 3D-model of the lower section displaying the neutral axis (the red line) of the L160 and L100 mm angle profiles to make the lattices specific for metal constructions.

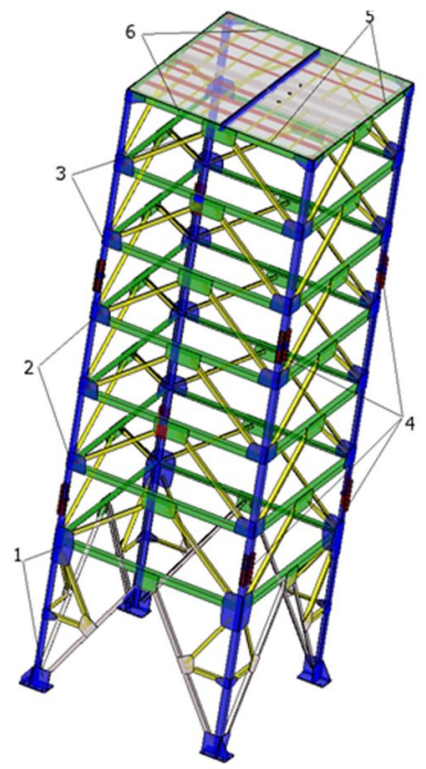

Figure 1a)

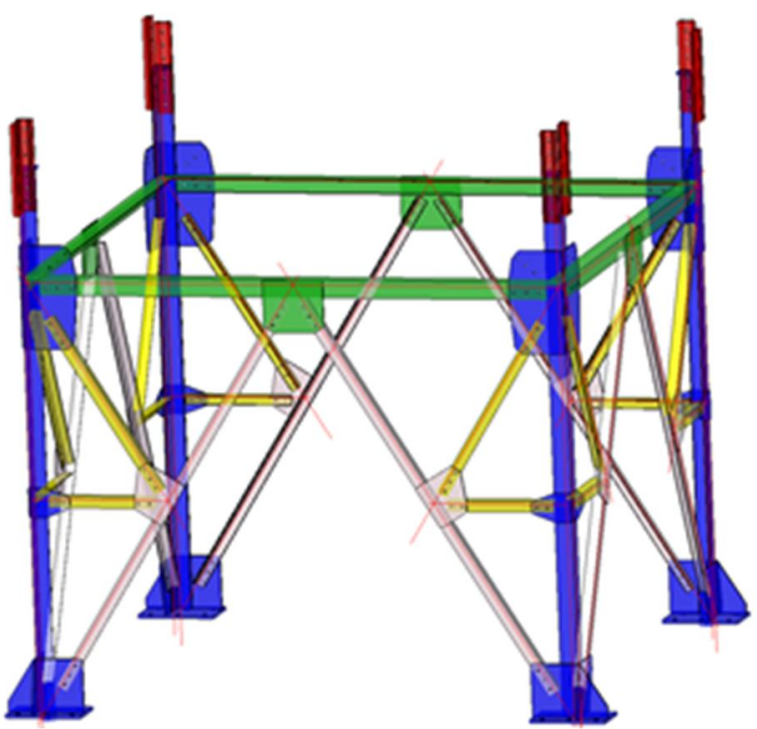

Figure 1b)

\section{Analytical model}

Figure 2 displays the calculation model with the geometrical sizes of the pit-head frame in which the stress acting upon the metal structure is determined. The forces exerted on the frame are the following: technological forces belonging to the hoisting cable, in the case the stuff is extracted by bucket and in the case the movable bridge is removed, these forces being transmitted to the pit-head frame through the bearings of the hoisting sheave and mass forces given by the weight of the frame and the components mounted on it.

The basis of reference in comparison with which the application points of the forces are defined is the ground 0.00 level, where the metal construction of the frame and its symmetry axes are designed. [2]

Maximal technological forces, applied in the symmetry centre of the hoisting sheave and transmitted to the frame through the two bearings of the hoisting sheave, are calculated 
for two situations: the first one dealing with the transportation of the rock or stuff by bucket, while the second one for putting on or removing the movable work bridge.

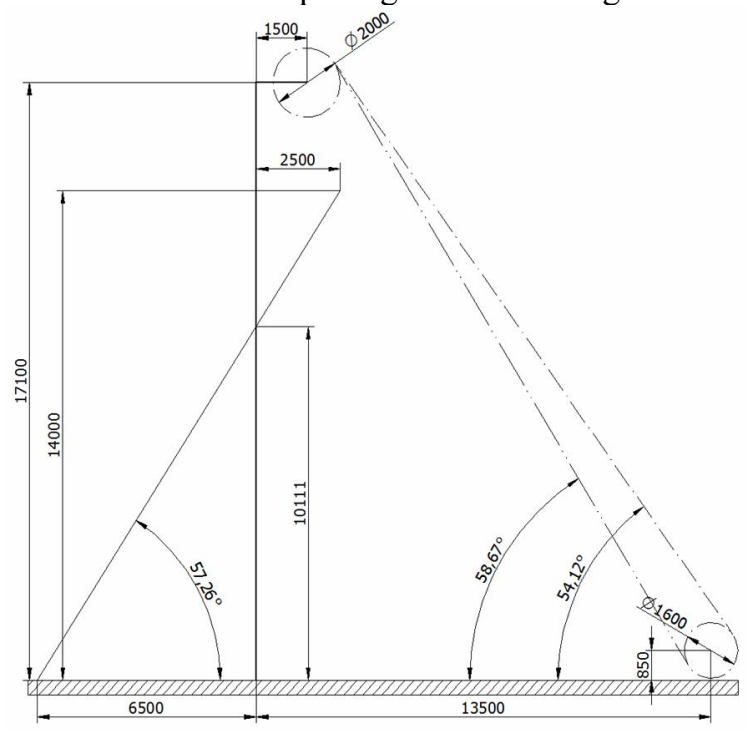

Fig. 2. Calculation model of the forces that are exerted on the frame

Taking into account the importance of the equipment, safety standards require a safety coefficient of 3 , especially due to the fact that it also involves the transportation of the employees; consequently, calculations adopt a dynamic coefficient of 1.6 with which the module of the technological forces used when calculating the metal structure is multiplied. For the verification calculation of the pit-head frame, the components of the technological forces applied in the centre of the hoisting sheave are: $F_{x}=19410 \mathrm{~N}$ and $F_{z}=59960 \mathrm{~N}$, in the case when the stuff is conveyed by bucket and $F_{x}=52220 \mathrm{~N}$ and $F_{z}=161300 \mathrm{~N}$, in the case of putting on or removing the movable bridge. [3, 4]

The fixing of the indeterminate, simple, static system in the Mohr-MaxvellVeresciaghin procedure, a series of forces are determined, as follows: axial forces, shearing forces, bending moments along the whole shape of the frame as well as the forces within the anchorage cables, which are all calculated for the two situations previously mentioned.

The geometric characteristics of the critical sections of the metal structure of the frame result when the utility software Solid Edge is used, which allows the direct reading of the inertia moments and of strength modules as compared to the horizontal axes $x$ and $y$, as well as the area of the sections and maximal distances to the middle fibre. $[5,6]$

\section{Analysis of the stresses and deformations within the metal structure of the frame in Cosmos Design Star program}

The finite elements structural analysis performed in Cosmos Design Star program allows the following types of analyses: linear and nonlinear static analysis; modal analysis, specific frequencies and vibration modes; buckling calculation; linear and nonlinear, permanent and transitory heat transfer; fluids flows; electromagnetic analysis. Linear static analysis, applied to the metal structure of the pit-head frame, deals with the following hypotheses: the static character of loadings application; the hypothesis of the linearity between loadings and the response issued by the body, in accordance to which tension $\sigma$ is 
directly proportional to deformation $\varepsilon, \sigma=E \cdot \varepsilon$, proportionality coefficient being the longitudinal elasticity module, $E$. [7]

The inner tensions occurring within the body by external loadings vary from one point to another and show the behaviour of the structure of the body at external stresses. The linear static analysis calculates stresses, displacements, strains, deformations and reaction forces under the effect of the loadings applied to the model. The use of Cosmos Design Star program allows the digitization of the metal structure of the pit-head frame (less the roof section), while also considering, besides the L160 and 1100 angle beams, the connection gussets, including the junction plates of the three sections of the frame. In accordance, a very fine digitization results, which, nonetheless, determines a very large number of knots and elements, more precisely: 1048971 knots and 538799 elements.

The application of the program to the entire structure of the frame determines the solving of 3,140,910 equations, which is far beyond the calculation power of a common computer, as Figure 3a) shows, exhibiting a screen capture that showing the end of the procedure without indicating the result. Figure $3 b$ ) shown one may notice the loading of the metal structure of the pit-head frame with the forces having resulted from putting on a movable bridge, both within the bearings of the hoisting sheave, and within anchorage cables, while the weight of the frame is not being considered. With a view to restraining the application of the program with the fine digitization under study, we shall consider only the first section of the frame, embedded in the concrete foundation, yet loaded with the real forces within the hoisting sheaves, the anchorage cables, including the weight of the frame, in the case of putting on the movable bridge; the forces under consideration are the ones in the application points at real distances. [8]

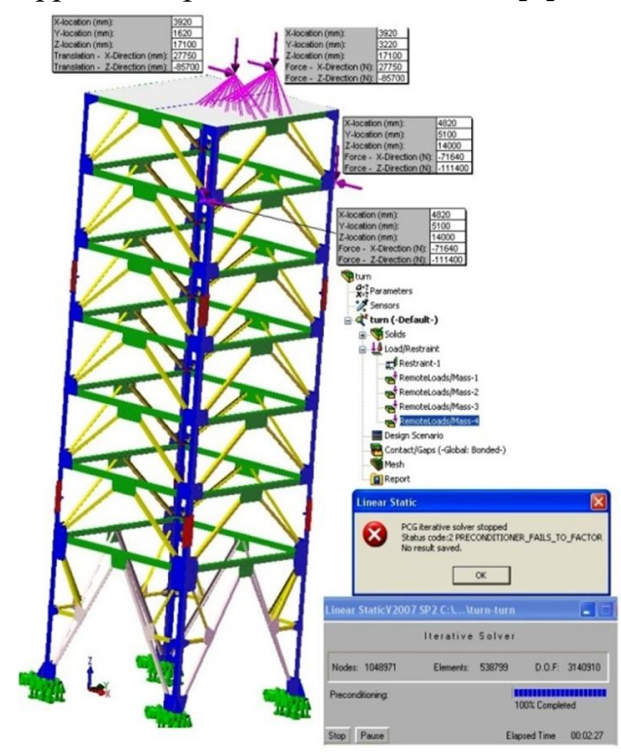

Figure 3a)

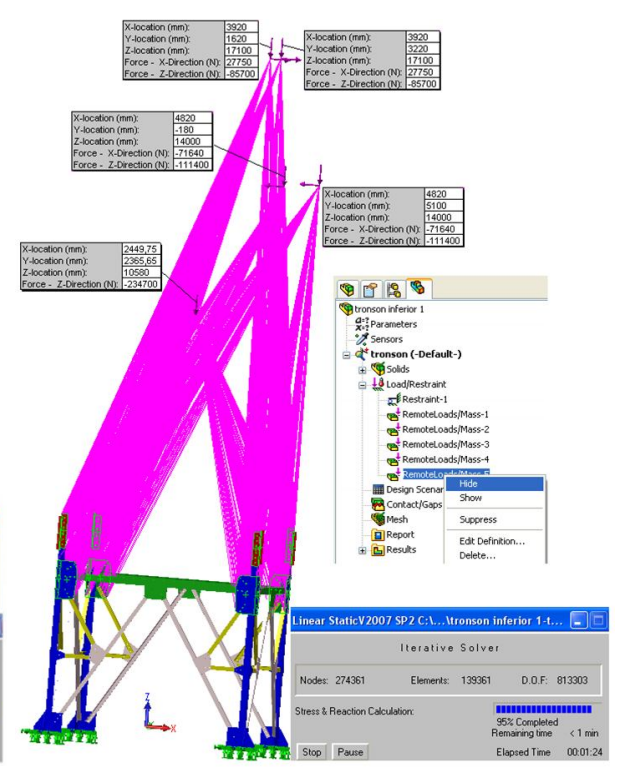

Figure 3b)

Fig. 4a) shown the equivalent stress in lower section, $\sigma \max =97.54 \mathrm{~N} / \mathrm{mm} 2$. Fig. $4 \mathrm{~b}$ ) shown the resultant of displacement on the lower section, $\delta \max =2.5 \mathrm{~mm}$. Fig. $4 \mathrm{c}$ ) shown the normal stress after $Z$ orientation in the lower section, $\sigma \max =40.12 \mathrm{~N} / \mathrm{mm} 2$, highlighting maximal stresses in the area where the frame is embedded. Fig. 4d) shown the equivalent tension on the lower section in the case when the weight of the frame is not considered, $\sigma \max =64.06 \mathrm{~N} / \mathrm{mm} 2$. 


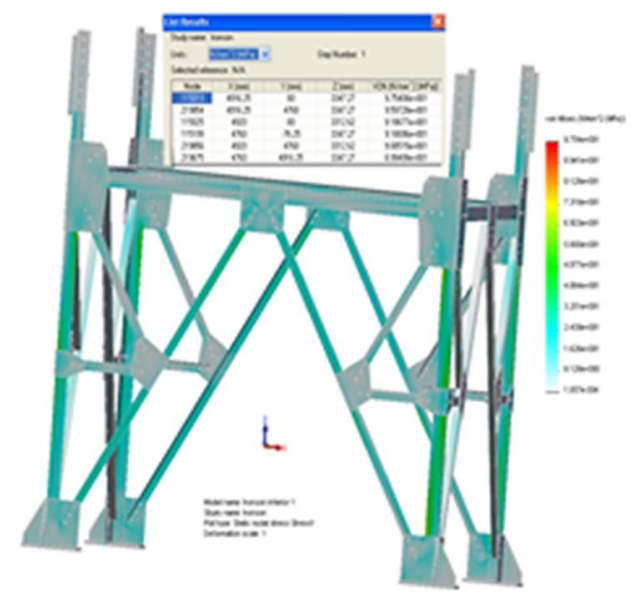

Figure 4a)

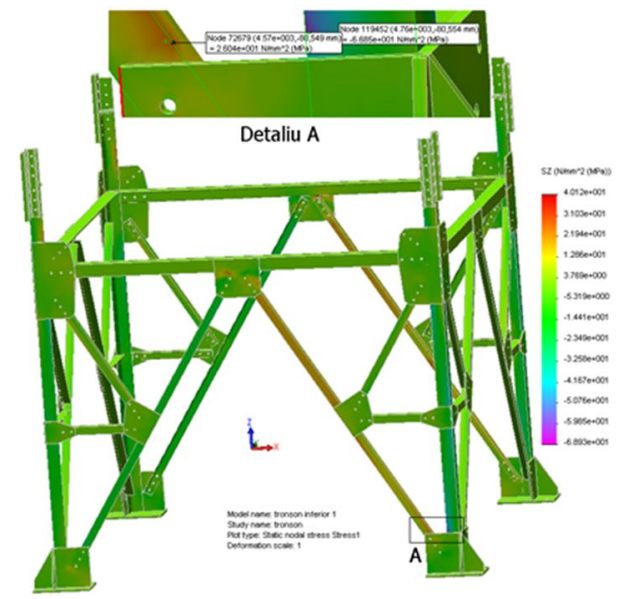

Figure 4c)

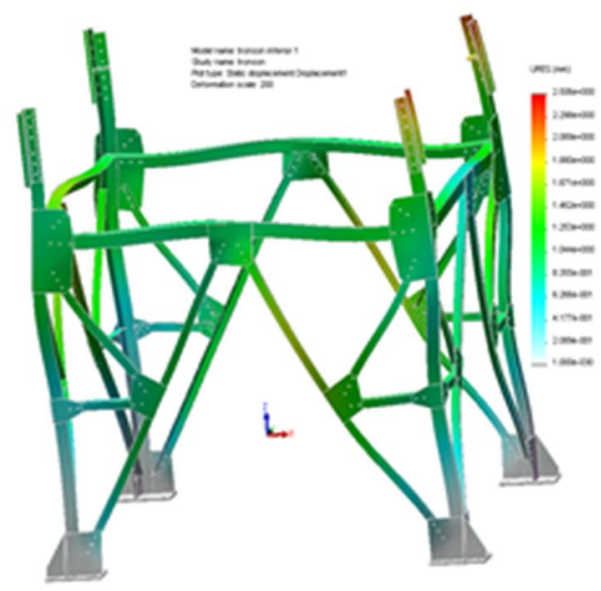

Figure 4b)

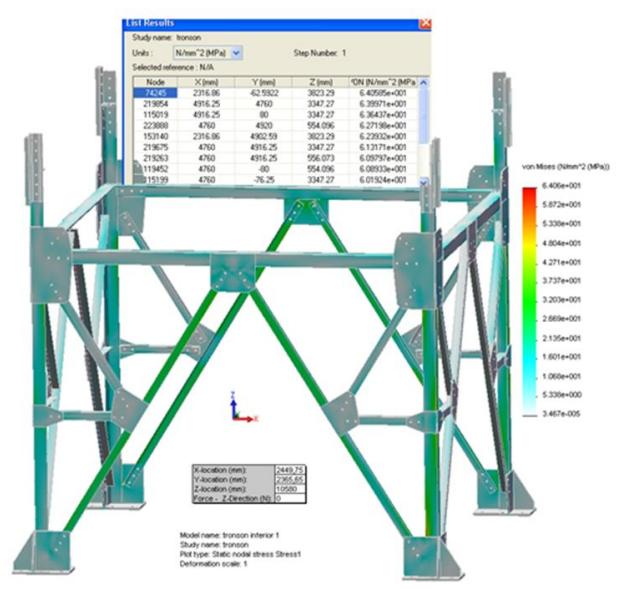

Figure 4d)

\section{Finite element analysis of the stresses and deformations of the metal structure of the frame using Abaqus program}

The utility software Abaqus FEA issued by Simulia provides a complete and flexible solution for understanding the detailed behaviour of a complex equipment upon which stress is exerted, with a view to refining the designing concepts and understanding the features of new materials or to simulating a heterogeneous manufacturing process.

Generally speaking, the analysis relying on the method of the finite element in Abaqus consists in three stages: pre-processing or modelling, which involves the creation of an input file containing the geometry of the structure to be analysed; the processing and finite element analysis that generates a visual output file; post-processing or report generating, which allows the visual editing of the results of the analysis.

Case I - The normal extraction situation involving the movement of the loaded bucket from the lowest digging level. The forces under consideration are the following ones: technological force given by the maximal load within the extraction cable, $F_{t}=30000 \mathrm{~N}$; tensile strength within each of the guide cables, $F_{g}=5000 \mathrm{~N}$; straining force of anchorage cables, $F_{a}=8000 \mathrm{~N}$. 
Figures 5a) shown the Von Mises stress within the metal construction of the frame, case $\mathrm{I}, \sigma \max =72.78 \mathrm{~N} / \mathrm{mm} 2$ and Figure $5 \mathrm{~b}$ ) display amplitude of the deformations of the metal construction of the frame, case I, $\delta \max =7.876 \mathrm{~mm}$.

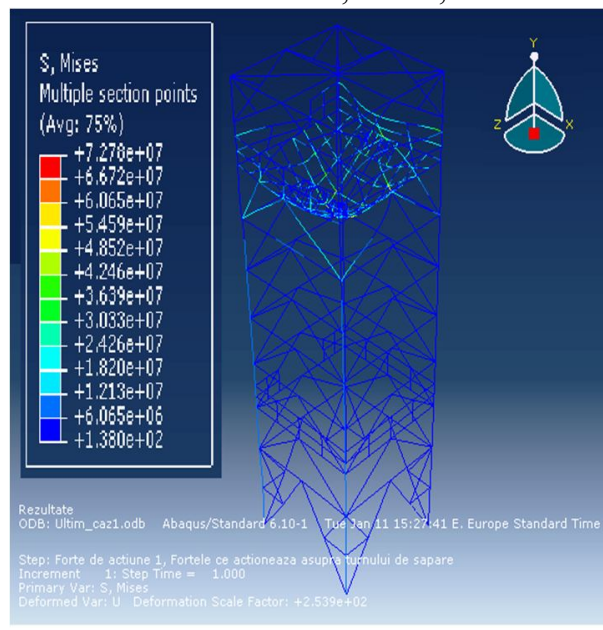

Figure 5a)

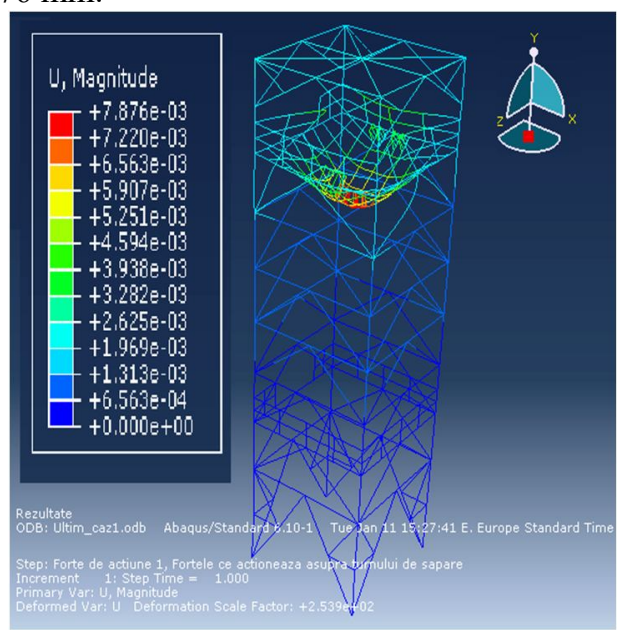

Figure 5b)

Case II - The normal extraction situation with the loaded bucket at the upper level of the frame. The forces under consideration are the following ones: technological force given by the maximal load of the extraction cable, $F_{t}=30000 \mathrm{~N}$; tensile force within each of the guiding cables, $F_{g}=5000 \mathrm{~N}$; straining force of anchorage cables, $F_{a}=8000 \mathrm{~N}$.

(Figure 6a) shown Von Mises stress within the metal construction of the frame, case II, $\sigma \max =66,89 \mathrm{~N} / \mathrm{mm} 2$ and figure $6 \mathrm{~b}$ ) display the amplitude of the deformations of the metal construction of the frame, case II, $\delta \max =7.245 \mathrm{~mm}$.

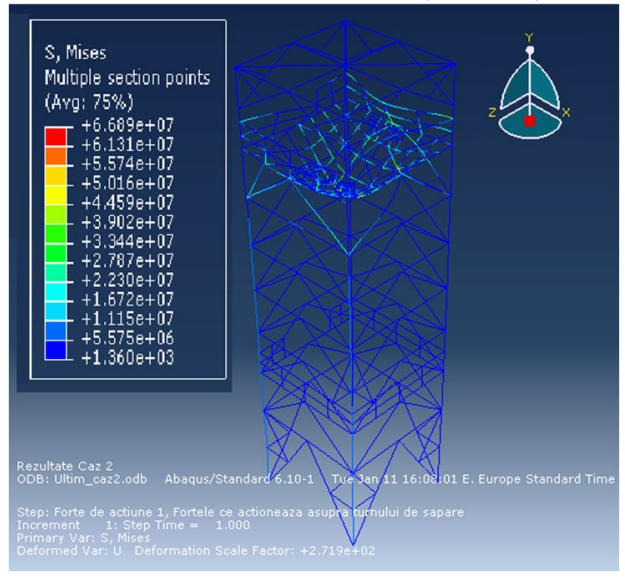

Figure 6a)

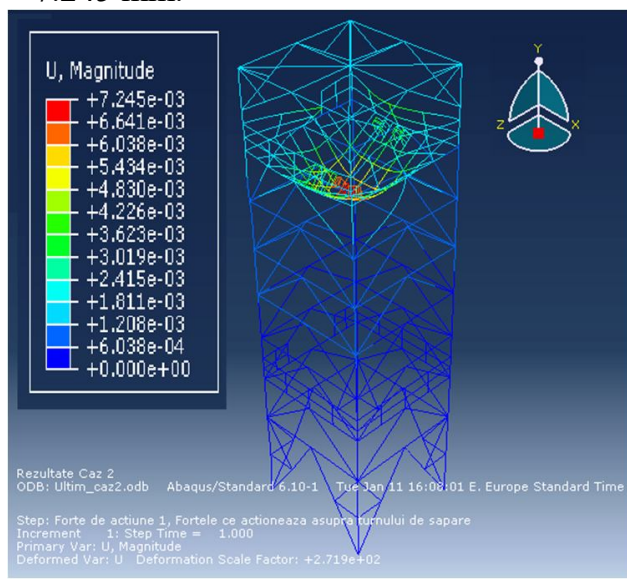

Figure 6b)

\section{Conclusions}

The goal of this work is to carry out the verification calculation of the metal structure of the pit-head frame, both through a classical analytical calculation and through the method of the finite element. The metal structure of the pit-head frame is modelled as a plane framework that represents a simple, undetermined static system, loaded with the 
technological forces that come out within the extraction cable and with the mass forces given by the weight of the frame.

When knowing the loadings and geometrical features of critical sections, through applying the theories specific for compound stresses, one may determine the tensions within the metal structure of the frame and, implicitly, the safety coefficients. The calculations carried out show values of safety coefficients over admissible values, even very high values in the case of bucket transportation, which is the most frequent case encountered during the use of the equipment; this fact shows that the pit-head frame is oversized. The calculations carried out show that the upper platform of the frame, on which the hoisting sheave and the four driving sheaves guiding the bucket's cables are mounted, do not hold good in the case it is made of OL 37, as the rest of the frame; superior steel is required, that is OL 52, in the case when the stresses are determined by the putting on of the mobile bridge. Maximal tensions within the structure of the frame come out in the area of the upper platform; this fact is also shown when applying the methods of studying the stresses and deformations through the finite elements, while using Cosmos Design Star and Abacus utility software.

The use of a finer digitization, through considering the L160 and L100 profiles of the junction plates, of the connecting fasteners between sections and of the connecting elements, determine a structure made of a very large number of knots and elements, which cannot be processed by a commonly used computer. The modelling carried out in this program was made for the first section of the frame, loaded with real loads, given by the technological forces applied when putting on the mobile bridge, the forces within the cables for the same situation, and the weight of the frame. The modelling shows that the maximal efforts come out in the area where the structure in embedded in the foundation, the values being under the admissible ones.

\section{References}

1. G. Muscă, Proiectarea asistată folosind Solid Edge (Junimea Publishing House, Iasi, 2006)

2. F. D. Popescu, S. M. Radu, Vertical hoist systems, New trends optimizations, (LAP LAMBERT Academic Publishing, Saarbrucken Germany, 2014)

3. F. D. Popescu, G. Dimirache, Instalaţii de transport pe verticală-Calcule de verificare şi dimensionare (Focus Publishing House, Petrosani, 2011)

4. F. Popescu, A. Andraş, I. Kertesz, The method of minimizing the calculated power of vertical transport installations, $17^{\text {th }}$ International Multidisciplinary Scientific GeoConference SGEM 2017, 17, 13, pp. 901-908, (2017)

5. C. D. Adam, Instalaţii de extractie miniere (Universitas Publishing House, Petrosani, 2008)

6. D. Radu, Rezistenţa materialelor (Universitas Publishing House, Petrosani, 2017)

7. F. D. Popescu, G. Dimirache, Instalaţii de transport pe verticală-Calcule de verificare şi dimensionare (Focus Publishing House, Petrosani, 2011)

8. PT-C $09-$ Technical prescriptions concerning the exploitation, maintenance and control of hoisting plants, cables and cable fastening devices.

9. Solid edge softer, https://solidedge.siemens.com/en/solutions/users/students/

10. Cosmo Design Star soft, http://www.cosmosm.com

11. Abaqus soft, https://academy.3ds.com/en/software/abaqus-student-edition. 